\title{
Algorithm for predicting threshold retinopathy of prematurity is insufficient and fundus examinations are still needed up to 31
} weeks

M Wirth ${ }^{1,2}$, A Naud $^{1}$, G Caputo $^{3}$, JM Hascoët $^{1,2}$

1 Department of Neonatology, University Hospital of Nancy, Nancy, France.

2. University of Lorraine, EA3450 - DevAH, Vandoeuvre les Nancy, France.

3. Department of Paediatric Ophthalmology, Adolphe de Rothschild Ophthalmological Foundation, Paris, France.

Short title: Algorithm for predicting retinopathy of prematurity

Corresponding author: M. Wirth, Department of Neonatology, University Hospital of Nancy, 10 rue du Dr Heydenreich, 54035 Nancy, France. Tel +33383343645. Fax +33383344411. 


\section{Abstract}

Aim: We evaluated the weight, insulin-like growth factor-1, neonatal, retinopathy of prematurity (WINROP) algorithm for very premature infants.

Method: Infants born before 32 weeks who had undergone fundus examinations in the neonatal intensive care unit at the University Hospital of Nancy were included in this French retrospective cohort study from July 2012 to July 2016 . We evaluated how well the WINROP software predicted threshold retinopathy of prematurity (ROP).

Results: We studied 570 infants with a mean gestational age of $28.7 \pm 1.8$ weeks and a mean birth weight of $1,110 \pm 297$ grams: $28.1 \%$ had ROP and $1.2 \%$ had threshold ROP. The overall WINROP sensitivity was $57.1 \%$, specificity was $46.0 \%$, predictive positive value was $1.3 \%$ and predictive negative value was $98.9 \%$. At more than 30 weeks of gestation or 1,250 grams, these figures rose to a respective specificity of $100 \%$ and $95.7 \%$ and respective predictive negative value of $100 \%$ and $100 \%$. There were independent associations between the severity of ROP and the Apgar Score at five minutes, the duration of oxygen therapy and non-invasive ventilation.

Conclusion: WINROP performed better on preterm infants born after 30 weeks or over $1,250 \mathrm{~g}$. Fundus examinations remain necessary for those born before 31 weeks or under $1,251 \mathrm{~g}$. 


\section{Key Notes}

- We evaluated the weight, insulin-like growth factor-1, neonatal, retinopathy of prematurity (WINROP) algorithm for very premature infants.

- Our study of 570 infants born before 32 weeks showed that WINROP was better at predicting risk of threshold retinopathy of prematurity of preterm infants born after 30 weeks or weighing over $1,250 \mathrm{~g}$.

- It is still necessary to carry out fundus examinations of preterm infants born before 31 weeks or weighing under $1,251 \mathrm{~g}$. 
Keywords Algorithm, Fundus examination, Premature infants, Retinopathy of prematurity, Screening 


\section{INTRODUCTION}

Retinopathy of prematurity (ROP) is one of the main causes of avoidable visual impairment in children (1). The unmodifiable risk factors initially described by the Australian and New Zealand Neonatal Network, back in 2005, were a birth weight at 1,500 grams or less and a gestational age of less than 33 weeks of gestation. They also noted that severity increased with increasing prematurity (2). The main modifiable risk factor that has been identified is oxygen $(3,4)$. Low serum insulin-like growth factor-1 concentration has also been shown to play an important role $(3,5)$. Other described risk factors have included ethnicity $(3,6)$ intra uterine growth restriction $(2,3,7)$, hyperglycaemia $(3,8-10)$, formula feeding, the lack of omega-3 long-chain polyunsaturated fatty acids in the diet $(3,4,11)$, infections $(3,4,10)$ and red blood cell transfusions $(3,4,10)$. Associated comorbidities that have been described are bronchopulmonary dysplasia, necrotising enterocolitis and intraventricular haemorrhage (3).

A prognostic classification was developed by the authors of the Early Treatment for Retinopathy of Prematurity study and this defined two types of severe ROP. These were threshold ROP that required treatment and pre-threshold ROP that risked becoming threshold ROP and required screening twice a week (12).

One study reported that less than $2 \%$ of children screened for ROP required treatment (13). The diagnostic performance was therefore low. On the other hand, the number of fundus examinations has been estimated to be 5.4 per infant (14). Fundus examinations are stressful for premature infants (15), so it is important to optimise screening.

The French Ophthalmology Society has produced new French guidelines in 2016 for screening ROP that have not yet been published. These recommend screening 
infants born before 31 weeks of gestation or with a birth weight below 1,251 grams at birth for ROP. They also state that infants with a birth weight between 1,251 and 2,000 grams should be screened if the infant presents with risk factors such as sepsis or has received prolonged oxygen therapy or prolonged vasopressor therapy.

Several algorithms for screening have been developed, including the free weight, insulin-like growth factor-1, neonatal, retinopathy of prematurity (WINROP) algorithm (16), which was developed by the The Sahlgrenska Center for Pediatric Ophthalmology Research at the University of Gothenburg, Sweden. WINROP was developed for infants born below 32 weeks of gestation and its aim was to predict the individual risk of threshold ROP by taking into account the infant's postnatal evolution $(17,18)$. It is based on weight and the blood levels of insulin-like growth factor-1. The latter are correlated with fetal and postnatal growth, making the assessment of weight gain sufficient when using WINROP $(5,19,20)$. WINROP is an inexpensive, simple, routine, fast, reproducible test that is carried out on a daily basis.

The aim of this study was to evaluate the performance of the WINROP algorithm with regard to predicting threshold ROP in very premature infants.

\section{PATIENTS AND METHODS}

This retrospective cohort study comprised infants born below 32 weeks of gestation and hospitalised in the neonatal intensive care unit at the University Hospital of Nancy, France, from July 2012 to July 2016 . They were included if their medical records included the results from a fundus examination for ROP carried out with the ophthalmic imaging system Retcam (Clarity Medical Systems, California, USA). Infants with other ophthalmological pathologies, genetic diseases, hydrocephalus and those who died before 40 weeks of gestation were excluded. 
During the study period our unit screened all premature infants born at up to 32 weeks of gestation or with a birth weight of up to 1,500 grams. The first examination took place at four weeks of actual age for infants born from 27 weeks of gestation and at an adjusted age of 31 weeks of gestation for infants born earlier. After that fundus examinations were carried out in accordance with international recommendations (2).

The haemoglobin oxygen saturation targets were $88-95 \%$ during this period. Infants were followed until 40 postmenstrual weeks and their weight was recorded on a weekly basis. We evaluated how effectively the WINROP algorithm was at predicting threshold retinopathy in the entire cohort, with regard to sensitivity, specificity, positive and negative predictive values. The gold standard was the clinical diagnosis according to good practice recommendations. We also specifically evaluated the performance of WINROP on the infants excluded by the new French guidelines, namely infants born at 31 or more weeks of gestation or with a birth weight of $1,251 \mathrm{~g}$ or more.

Perinatal drugs and environmental data were collected from the infants' files and were evaluated by a descriptive analysis with means, standard deviations, medians based on first and third quartiles and percentages. These data were analysed with regard to severe ROP, which was defined by threshold and pre-threshold ROP. The quantitative variables were compared by the Student's t parametric test, while the qualitative variables were compared by using the chi-square test after verification of the application conditions. In the case of non-Gaussian populations, the Mann and Whitney, Kruskal Wallis and chi-square tests were used. Risk factors for any ROP with a $p$ value of $<0.1$ in the bivariate analysis were then included in a stepwise multiple linear regression model with tolerance set at $10^{-5}$, the probability to remove 
set at 0.15 and $95 \%$ confidence intervals. The threshold for statistical significance was set at $p<0.05$.

Parents were informed of this study by a specific newsletter and provided written consent. This research was performed in accordance with the Declaration of Helsinki and registered at ClinicalTrials.gov (number: NCT03347799).

\section{RESULTS}

We enrolled 570 infants and the recruitment process is detailed in Figure 1. The mean gestational age and birth weight were $28.7 \pm 1.8$ weeks of gestation and 1,110 \pm 297 grams. The characteristics of our study population and the associations between ROP and perinatal factors in the bivariate analysis are reported in Table 1.

The average number of fundus examination per infant was $2.9 \pm 2.2$ and we found that $28 \%$ of the infants had various stages of ROP. Threshold ROP was found in $1.2 \%$ of the infants and pre-threshold ROP was found in $5.3 \%$. The mean corrected age at the most severe stage of ROP was $37 \pm 3$ weeks of gestation for threshold ROP, $34 \pm 2$ weeks of gestation for pre-threshold ROP and $35 \pm 3$ weeks of gestation for other ROP. The high-risk alarm for the WINROP algorithm was triggered in 54\% of cases. Those alarms were not associated with sex, multiple pregnancy, antenatal corticosteroid, intraventricular haemorrhage and early-onset sepsis. However they were significantly associated $(p<0.05)$ with the following: a lower gestational age (100\%, 100\%, 98.0\%, 92.9\%, 80.9\%, $74.0 \%, 11.0 \%$ and $0 \%$ at respectively 24,25 , $26,27,28,29,30$ and 31 weeks of gestation), intrauterine growth restriction (100\% versus $45.9 \%$ ), bronchopulmonary dysplasia (63.9\% versus $36.7 \%)$, postnatal corticosteroid (79.1\% versus $20.9 \%)$, red blood cells transfusion $(73.1 \%$ versus $26.9 \%)$, medical treatment of patent ductus arteriosus (70.3\% versus $29.7 \%$ ), 
surgical treatment of patent ductus arteriosus (73.7\% versus $26.3 \%)$, late-onset sepsis $(68.2 \%$ versus $31.8 \%)$, blood inflammation $(66.0 \%$ versus $34.0 \%)$, necrotising enterocolitis (71.3\% versus $28.8 \%)$, hyperglycaemia ( $86.1 \%$ versus $13.9 \%)$ and insulin therapy ( $86.7 \%$ versus $13.3 \%)$.

The delay between birth and the trigger was $13 \pm 1$ days. The delay between the trigger and the discovery of all stages of ROP was $33 \pm 20$ days and it was $41 \pm 24$ days for the most severe stage of ROP. The delay between the trigger and the treatment of ROP, when necessary, was $64 \pm 52$ days.

The WINROP trigger was associated with threshold ROP in four out of 308 alarms and threshold ROP was present in three out of 262 infants without alarms. Thus, the WINROP sensitivity was $57.1 \%$, the specificity was $46.0 \%$, the predictive positive value was $1.3 \%$ and the predictive negative value was $98.9 \%$. No threshold ROP was found for infants born at 31 weeks of gestation or more or weighing 1,251 grams or more and the specificity was $100 \%$ and $95.7 \%$, respectively, and the predictive negative values were both $100 \%$.

Severe ROP was associated with a lower gestational age and a lower birth weight than no severe ROP or no ROP and the figures were $26.6 \pm 1.4$ versus $28.8 \pm 1.7$ weeks of gestation $(p<0.001)$ and $831 \pm 162$ versus $1,166 \pm 292$ grams $(p<0.001)$. The factors associated with severe ROP are presented in Table 1. We did not show any overall relationship between infants with intrauterine growth restriction and severe ROP. However, the number of infants with an intrauterine growth restriction differed between infants with a gestational age of below 28 weeks and the group of infants from 28 weeks of gestation ( $43.3 \%$ versus $8.4 \%$ respectively). When we considered gestational age as a confounding factor, there was a significant relationship between infants with intrauterine growth restriction and severe ROP 
$(r=0.291, p=0.037)$. Severe ROP was not associated with necrotising enterocolitis, except in most severe forms of stages IIb, IIla and IIIb, when they were $16.7 \%$ versus $9.5 \%, 16.7 \%$ versus $1.4 \%$ and $16.7 \%$ versus $4.1 \%$, respectively ( $p=0.047$ ). Multivariate stepwise linear regression showed an independent association between the severity of ROP and low birth weight, a low Apgar Score at five minutes, a longer duration of oxygen therapy, a longer duration of postnatal corticosteroids and the duration of non-invasive ventilation $(r=0.569, p<0.001)$.

Oxygen therapy duration was delivered for a mean of $32 \pm 25$ days in infants without ROP versus $65 \pm 28$ days in infants with any ROP ( $p<0.001)$ versus $83 \pm 23$ days in infants with severe ROP $(p<0.001)$.

\section{DISCUSSION}

The incidence of threshold ROP in our cohort agreed with the literature (13). The point at which high-risk alarms were triggered, the time between alarm triggers and treatment and the performance of WINROP were consistent with several studies (21-23). Unlike the initial validation papers $(16,22)$, our study showed that WINROP was not perfect for screening threshold ROP and these findings agreed with a paper published in 2018 (24). Thus, with regard to the limits of gestational age and birth weight in the new but unpublished French guidelines on screening, we confirm that fundus examination remains necessary for infants born before 31 weeks of gestation or with birth weight of up to 1,250 grams. Nevertheless, the absence of WINROP triggering may allow waiving fundus examination for infants born at 31 weeks of gestation onwards or with birth weight of $1,251 \mathrm{~g}$ or more. However, WINROP can only be used to screen the infants born before 32 weeks of gestation (22). This leaves a grey area for infants born from 32 weeks of gestation onward who have a birth weight of between 1,251 and 2,000 grams. 
The use of the WINROP algorithm is based upon gestational age, birth weight and weekly weight measurements $(22,25)$. In our study the high-risk WINROP alarm was associated with intra uterine growth restriction, which was not associated with severe ROP. However, WINROP was associated with all situations linked to bad anabolism, because it is based on weight gain, which is impaired in these situations. This suggests that the impact of birth weight may be given too much emphasis in the algorithm, which is based on a standard weight range for gestational age. It appears that postnatal weight gain may be more important than birth weight. For example, Jung et al showed that infants born before 28 weeks of gestation, with a birth weight that was over the $70^{\text {th }}$ percentile, were not identified by WINROP as having a high risk of developing severe ROP (23).

WINROP could be improved by considering additional parameters, including those identified by our multivariate analysis. For example, the Apgar score at five minutes, any use of oxygen therapy and any use of post-natal corticosteroids could easily be added to the algorithm.

WINROP is free, it is simple to use with an online monitoring system and it can be used on just weekly weight gain measurements $(22,25)$. So, even if WINROP is not supposed to be used on its own for screening ROP, it can help to target high-risk infants in centres that do not have easy access to ophthalmic screening.

Otherwise, the goal of this algorithm should be, at the very least, to limit the number of eye fundus examinations that are carried out. It would be interesting to evaluate the result of using WINROP and just one fundus examination. We propose that this examination could be carried out at 32 weeks of gestation as this is the mean age at the most serious stage of ROP. 
According to the literature a number of factors seem to be associated with severe ROP, such as multiple pregnancies, red blood cell transfusions, sepsis, hyperglycaemia, intraventricular haemorrhage, bronchopulmonary dysplasia and patent ductus arteriosus $(3,4,8-10,12)$. In addition, severe ROP has been associated with severe enterocolitis, from stage IIb to IIIb (3). This could be explained by common factors like associated inflammation and poor weight gain. When we considered gestational age as a confounding factor, we also found a significant relationship between infants with intrauterine growth restrictions and severe ROP. This finding was consistent with the literature $(2,3,7,26)$.

In our bivariate analysis, inflammation and sepsis were associated with severe ROP. Postnatal inflammation has been reported to increase severe ROP, with abnormal retinal vascular development and vessel anastomosis (27). Our study showed that late-onset sepsis, but not early-onset sepsis, was associated with severe ROP. So, the timing of the inflammation seems to play an important role in the development of severe ROP. Beaudry-Richard et al argued that early onset sepsis may be overshadowed by early inflammation, which is a major cause of preterm delivery especially for very preterm infants. As a result, early inflammation should be regarded as a main risk factor for ROP. However, the mechanism of early inflammation that triggers detrimental effects in the retina during ROP is still unclear and difficult to be evaluated and predicted (28).

In accordance with the literature (3,8-10), hyperglycaemia was also associated with severe ROP in our study. One study has suggested that these two factors are potentially linked by the inhibition of angiogenesis, which induces inflammation and neuronal degeneration in the retina (8). 
The use of postnatal corticosteroids was associated with severe ROP in our study and this has previously been reported in the literature (29). Given the importance of inflammation in the pathophysiological mechanism of ROP, it would be interesting to investigate whether corticosteroids are a real risk factor for severe ROP or whether inflammation appears as a confounding factor in this relationship.

Likewise, hyperglycaemia $(3,8-10)$ and the use of insulin were associated with severe ROP in our cohort and in the literature. However, a detailed study is required to understand the physiopathological mechanism of their relative role with regard to ROP. Some studies have suggested insulin, rather than hyperglycaemia, as a risk factor (30), but others have stated that insulin is a protective factor for severe ROP in patients with hyperglycaemia $(8,9)$.

The strengths of our study were that our hospital records contained detailed eye fundus images and we were able to study a large population over a number of years. The main imitation was the retrospective nature of our study.

\section{CONCLUSION}

Using the WINROP algorithm at 31 weeks of gestation onwards or with birth weight of $1,251 \mathrm{~g}$ or more, on our cohort of preterm infants, provided a respective specificity of $100 \%$ and $95.7 \%$ and respective predictive negative value of $100 \%$ and $100 \%$. However, fundus examinations remain necessary for those born before 31 weeks of gestation or weighing under $1,251 \mathrm{~g}$. 


\section{ACKNOWLEDGEMENTS}

We thank research nurse S Guignon and A F Andre for their assistance with the data management. 


\section{ABBREVIATIONS}

ROP, Retinopathy of prematurity; WINROP, weight, insulin-like growth factor-1, neonatal retinopathy of prematurity. 


\section{CONFLICT OF INTERESTS}

The authors have no conflict of interest to declare.

\section{FUNDING}

This study did not receive any specific funding. 


\section{REFERENCES}

1. Kong L, Fry M, Al-Samarraie M, Gilbert C, Steinkuller PG. An update on progress and the changing epidemiology of causes of childhood blindness worldwide. $J$ AAPOS 2012; 16: 501-7.

2. Darlow BA, Hutchinson JL, Henderson-Smart DJ, Donoghue DA, Simpson JM, Evans NJ, et al. Prenatal risk factors for severe retinopathy of prematurity among very preterm infants of the Australian and New Zealand Neonatal Network. Pediatrics. 2005 115: 990-6.

3. Hellström A, Smith LEH, Dammann O. Retinopathy of prematurity. Lancet. 2013 382: $1445-57$.

4. Fang JL, Sorita A, Carey WA, Colby CE, Murad MH, Alahdab F. Interventions To Prevent Retinopathy of Prematurity: A Meta-analysis. Pediatrics 2016; 137: e20153387.

5. Hellström A, Engström E, Hård A-L, Albertsson-Wikland K, Carlsson B, Niklasson A, et al. Postnatal serum insulin-like growth factor I deficiency is associated with retinopathy of prematurity and other complications of premature birth. Pediatrics 2003;112: 1016-20.

6. Husain SM, Sinha AK, Bunce C, Arora P, Lopez W, Mun KS, et al. Relationships between Maternal Ethnicity, Gestational Age, Birth Weight, Weight Gain, and Severe Retinopathy of Prematurity. J Pediatr 2013; 163: 67-72.

7. Dhaliwal CA, Fleck BW, Wright E, Graham C, Mclntosh N. Retinopathy of prematurity in small-for-gestational age infants compared with those of appropriate size for gestational age. Arch Dis Child Fetal Neonatal Ed 2009; 94: F193-5.

8. Kermorvant-Duchemin E, Pinel AC, Lavalette S, Lenne D, Raoul W, Calippe B, et al. Neonatal hyperglycemia inhibits angiogenesis and induces inflammation and neuronal degeneration in the retina. PloS One 2013; 8:e79545.

9. Mohamed S, Murray JC, Dagle JM, Colaizy T. Hyperglycemia as a risk factor for 
the development of retinopathy of prematurity. BMC Pediatr 2013; 13: 78.

10. Leviton A, Dammann O, Engelke S, Allred E, Kuban KCK, O'Shea TM, et al. The clustering of disorders in infants born before the 28th week of gestation. Acta Paediatr 2010; 99: 1795-800.

11. Kermorvant-Duchemin E, Sennlaub F, Sirinyan M, Brault S, Andelfinger G, Kooli A, et al. Trans-arachidonic acids generated during nitrative stress induce a thrombospondin-1-dependent microvascular degeneration. Nat Med 2005; 11: 133945.

12. Early Treatment For Retinopathy Of Prematurity Cooperative Group. Revised indications for the treatment of retinopathy of prematurity: results of the early treatment for retinopathy of prematurity randomized trial. Arch Ophthalmol 2003; 121: $1684-94$.

13. Lala-Gitteau E, Majzoub S, Saliba E, Pisella P-J. [Epidemiology for retinopathy of prematurity: risk factors in the Tours hospital (France)]. J Fr Ophtalmol 2007; 30: 366-73.

14. Holmström G, Hellström A, Jakobsson $P$, Lundgren $P$, Tornqvist $K$, Wallin A. Evaluation of new guidelines for ROP screening in Sweden using SWEDROP - a national quality register. Acta Ophthalmol 2015; 93: 265-8.

15. Laws DE, Morton C, Weindling M, Clark D. Systemic effects of screening for retinopathy of prematurity. Br J Ophthalmol 1996; 80: 425-8.

16. Löfqvist C, Hansen-Pupp I, Andersson E, Holm K, Smith LEH, Ley D, et al. Validation of a new retinopathy of prematurity screening method monitoring longitudinal postnatal weight and insulinlike growth factor I. Arch Ophthalmol 2009; 127: $622-7$.

17. Löfqvist C, Andersson E, Sigurdsson J, Engström E, Hård A-L, Niklasson A, et al. Longitudinal postnatal weight and insulin-like growth factor I measurements in the prediction of retinopathy of prematurity. Arch Ophthalmol 2006; 124: 1711-8. 18. Wu C, Vanderveen DK, Hellström A, Löfqvist C, Smith LEH. Longitudinal 
postnatal weight measurements for the prediction of retinopathy of prematurity. Arch Ophthalmol 2010; 128: 443-7.

19. Lineham JD, Smith RM, Dahlenburg GW, King RA, Haslam RR, Stuart MC, et al. Circulating insulin-like growth factor I levels in newborn premature and full-term infants followed longitudinally. Early Hum Dev 1986; 13: 37-46.

20. Langford K, Nicolaides K, Miell JP. Maternal and fetal insulin-like growth factors and their binding proteins in the second and third trimesters of human pregnancy. Hum Reprod 1998; 13: 1389-93.

21. Koçak N, Niyaz L, Ariturk N. Prediction of severe retinopathy of prematurity using the screening algorithm WINROP in preterm infants. J AAPOS 2016; 20: 4869.

22. Wu C, Löfqvist C, Smith LEH, VanderVeen DK, Hellström A. Importance of Early Postnatal Weight Gain for Normal Retinal Angiogenesis in Very Preterm Infants. Arch Ophthalmol 2012; 130: 992-9.

23. Jung JL, Wagner BD, McCourt EA, Palestine AG, Cerda A, Cao JH, et al. Validation of WINROP for detecting retinopathy of prematurity in a North American cohort of preterm infants. J AAPOS 2017; 21: 229-33.

24. Chaves-Samaniego MJ, Gómez Cabrera C, Chaves-Samaniego MC, Escudero Gómez J, García Campos JM, Muñoz Hoyos A et al. Multicenter validation study of the WINROP algorithm as a method for detecting retinopathy of prematurity. J Mat Foetal Neon Med 2018; 19: 1-5.

25. Löfqvist C, Hansen-Pupp I, Andersson E, Holm K, Smith LEH, Ley D, et al. Validation of a New Retinopathy of Prematurity Screening Method Monitoring Longitudinal Postnatal Weight and Insulinlike Growth Factor I. Arch Ophthalmol 2009; 127: 622-7.

26. Guellec I, Lapillonne A, Marret S, Picaud JC, Mitanchez D, Charkaluk ML, et al. Effect of Intra- and Extrauterine Growth on Long-Term Neurologic Outcomes of Very Preterm Infants. J Pediatr 2016; 175: 93-9. 
27. Tremblay S, Miloudi K, Chaychi S, Favret S, Binet F, Polosa A, et al. Systemic inflammation perturbs developmental retinal angiogenesis and neuroretinal function. Invest Ophthalmol Vis Sci 2013; 54: 8125-39.

28. Beaudry-Richard A, Nadeau-Vallée M, Prairie É, Maurice N, Heckel É, Nezhady M et al. Antenatal IL-1-dependent inflammation persists postnatally and causes retinal and sub-retinal vasculopathy in progeny. Sci Rep 2018; 8: 11875.

29. Movsas TZ, Spitzer AR, Gewolb IH. Postnatal corticosteroids and risk of retinopathy of prematurity. J AAPOS 2016;20: 348-52.

30. Lee JH, Hornik CP, Testoni D, Laughon MM, Cotten CM, Maldonado RS, et al. Insulin, Hyperglycemia, and Severe Retinopathy of Prematurity in Extremely LowBirth-Weight Infants. Am J Perinatol 2016;33: 393-400 
Table 1: Factors associated with severe ROP

\begin{tabular}{|l|c|c|c|c|}
\hline \multicolumn{1}{|c|}{ Perinatal factors } & $\begin{array}{c}\% \\
\mathbf{( n = 5 7 0 )}\end{array}$ & $\begin{array}{c}\text { No ROP / other } \\
\text { ROP }\end{array}$ & $\begin{array}{c}\text { Severe ROP } \\
(\mathbf{n = 3 7})\end{array}$ & $\begin{array}{c}\mathbf{p} \\
\text { values }\end{array}$ \\
\hline Sex, male & $52.5 \%$ & $53.5 \%$ & $37.8 \%$ & 0.088 \\
\hline $\begin{array}{l}\text { Gestational age <31 weeks of } \\
\text { gestation }\end{array}$ & $82.6 \%$ & $81.4 \%$ & $100 \%$ & 0.004 \\
\hline Intrauterine growth restriction & $15.3 \%$ & $15.2 \%$ & $16.2 \%$ & 0.871 \\
\hline Multiple pregnancy & $30.7 \%$ & $29.5 \%$ & $48.6 \%$ & 0.025 \\
\hline Antenatal corticosteroid & $86.8 \%$ & $87.7 \%$ & $83.8 \%$ & 0.717 \\
\hline Postnatal corticosteroid & $22.6 \%$ & $18.6 \%$ & $81.1 \%$ & $<0.001$ \\
\hline Intraventricular haemorrhage & $25.6 \%$ & $24.6 \%$ & $40.5 \%$ & 0.031 \\
\hline Red blood cells transfusion & $49.0 \%$ & $45.5 \%$ & $100 \%$ & $<0.001$ \\
\hline $\begin{array}{l}\text { Bronchopulmonary dysplasia } \\
\text { (oxygen > 28 days) }\end{array}$ & $63.2 \%$ & $61.1 \%$ & $91.9 \%$ & $<0.001$ \\
\hline Use of vasopressor therapy & $19.7 \%$ & $16.7 \%$ & $62.2 \%$ & $<0.001$ \\
\hline Medical treatment of PDA & $24.2 \%$ & $21.0 \%$ & $70.3 \%$ & $<0.001$ \\
\hline Surgical treatment of PDA & $10.0 \%$ & $7.1 \%$ & $51.4 \%$ & $<0.001$ \\
\hline Early-onset sepsis & $10.5 \%$ & $10.3 \%$ & $13.5 \%$ & 0.576 \\
\hline Late-onset sepsis & $50.1 \%$ & $46.8 \%$ & $97.3 \%$ & $<0.001$ \\
\hline $\begin{array}{l}\text { Blood inflammation (CRP }>30 \\
\text { mg/l) }\end{array}$ & $46.2 \%$ & $44.2 \%$ & $75.0 \%$ & $<0.001$ \\
\hline Necrotising enterocolitis & $14.2 \%$ & $14.0 \%$ & $16.2 \%$ & 0.710 \\
\hline Hyperglycaemia (>11 mmol/l) & $20.2 \%$ & $17.3 \%$ & $63.9 \%$ & $<0.001$ \\
\hline Insulin therapy & $15.8 \%$ & $12.8 \%$ & $59.5 \%$ & $<0.001$ \\
\hline
\end{tabular}

CRP: C-Reactive Protein; PDA: Patent Ductus Arteriosus; 


\section{Figure legends}

Figure 1: Flow-chart 